\title{
Fertility and Household Poverty in Kenya: A Comparative Analysis of Coast and Western Provinces
}

\author{
George O. Odwe \\ Population Studies and Research Institute, University of Nairobi \\ P. O Box, 30197-00100, Nairobi-Kenya \\ Email: godweus@yahoo.com
}

\begin{abstract}
This paper examined the relationship between household poverty and fertility and tested whether the correlation between these two variables depend on the period and context. Using the Kenya Demographic and Health Survey dataset, a multivariate Poisson regression model was used to show the relationship between household poverty and fertility in Coast and Western provinces. The findings show that household poverty was a key factor in stalling fertility decline in Coast and Western provinces. Education is a significant determinant of fertility in Coast province while its effect diminishes over time in Western province. In both regions, child mortality appears to push up the fertility especially among poor households. Furthermore, the household poverty effects seem to be more pronounced in recent past than in the earlier periods (1989-1998). The study underscores that special attention and a targeting are necessary to meet the needs of the poor and reduce inequalities related to poverty that affect the possibilities of access to education and health services.
\end{abstract}

Keywords: Households, Poverty, Fertility, child mortality, Kenya

\section{Résumé}

Ce papier examine la relation entre la pauvreté des ménages et leur fécondité et a testé si cette corrélation entre ces deux variables dépendait de la période et du contexte. Utilisation de l'ensemble de données Enquête Démographique et de Santé du Kenya, un modèle multivarié de régression de Poisson a été utilisé pour montrer la relation entre la pauvreté des ménages et de la fertilité dans les provinces de l'Ouest et de la Côte. Les résultats montrent que la pauvreté des ménages a été un facteur clé dans l'amorce de la baisse de la fécondité dans les provinces côtière et Ouest du Kenya. L'éducation est un déterminant important de la fertilité dans la province côtière tandis que son effet diminue au fil du temps dans la province de l'Ouest. Dans les deux régions, la mortalité infantile semble augmenter le niveau de fécondité, en particulier dans les les ménages pauvres. En outre, les effets de la pauvreté des ménages semblent être plus prononcés dans le passé récent que dans les périodes lointaines(19891998). L'étude souligne qu'une attention particulière ainsi qu'un ciblage sont nécessaires pour répondre aux besoins des pauvres et réduire les inégalités liées à la pauvreté qui influent sur les possibilités d'accès à l'éducation et aux services de santé.

Mots-clés: ménages, pauvreté, fertilité, La mortalité infantile, Kenya

\section{Introduction}

Fertility decline has taken place in many countries in the world. Indeed, fertility has dropped below the replacement level in a number of developed countries (Lutz, O'Neill and Scherbov 2003). The decline has been attributed to increased empowerment of women through education and access to modern family planning. Studies also point to a global economic system making children more costly (Caldwell and Schindlmayr 2003). In Kenya, a rapid fertility decline was witnessed by the end of 1980s and early 1990s. The total fertility rate (TFR) defined as the average number of children a woman would have if she went through her entire reproductive period (15-49 years) reproducing at the prevailing ASFR declined from a high of 8.1 children per woman in the late 1970s, through 6.7 at the end of the 1980s, to 4.7 during the last half of the 1990s. Following this decline, TFR was projected to reach 3.2 children per woman by 20I5-2020 (CBS, MOH and ORC Macro 2004). However, fertility decline stalled and remained high in the late 1990's, a situation also observed in other sub-Saharan countries such as Zimbabwe and Ghana (Bongaarts 2006). The stall was not only a phenomenon in subSaharan Africa, but the high level at the stall was unique for the region (Bankole and Audam 2009).

Fertility decline in Kenya have not been homogeneous within the regions and continue to 
follow different pathways (Blacker 2002). Two regions, Western and Coast, highlight these differences. Western Province' had initially a rapid fertility decline from 8.I in 1989 to 5.6 in 1998; however, this came to a halt by the end of the 1990's. Indeed fertility increased slightly to 5.8 in 2003. In contrast, Coast Province has had modest change in fertility in the last two decades -Fertility declined by only II percent between 1989 to 2008/9 -the lowest decline recorded compared to other provinces excluding North Eastern province (KNBS and ICF Macro 20I0). In both regions, poverty is widespread and child mortality remains high. While the two regions marked the extremes of national variation in fertility levels by the end of the 1980s; both areas currently have higher fertility than the national average. Analysis of the relationship between fertility and household poverty is necessary for the establishment of causes of wide regional fertility differentials, slow pace of decline in some regions, and stall in fertility decline in the recent past, especially during 1998-2003.This study aims at disentangling the role of poverty in derailing fertility decline. Two fundamental questions are key for the present study. First, the study examines whether the relationship between poverty and fertility is context specific. Second, the study examines possible pathways through which poverty influences fertility in Coast and Western regions. Overall, the study aims to gain further insights into the specificities of the recent stall in fertility decline in Kenya using successive KDHS data from Coast and Western provinces.

A number of studies exist that document factors responsible for Kenyan fertility transition. According to (Brass and Jolly 1993), the high fertility pattern experienced in Kenya during the post-colonial era was attributed to the socio-economic development immediately Kenya gained her independence. During this period, there was an increase in living standards accompanied by a decline in child mortality. Other studies on the downward trend in fertility observed in the 1980s linked the decline to the use of contraceptive methods (Blacker 2002; Cross, Obungu and Kizito, 1991; Robinson 1992), postpartum infecundibility and changes in marital patterns (Macrae, Bauni and Blacker 200I). Post-partum infecundity was considered the most significant fertility inhibiting factor then, however, contraceptive use was found to have overtaken marriage as the second most important determinant responsible for the incipient fertility decline.

\footnotetext{
' Kenya was divided into eight administrative units known as provinces before the constitution of Kenya 2010, was promulgated.
}

In the last few decades, debates on situations of fertility stalls or reversals of have been the focus of fertility research in sub-Saharan Africa. Westoff and Cross (2006) provided a detailed analysis of the stall in Kenya between 1998 and 2003 while other researchers focused on the reasons behind the stall (Bongaarts 2006; Garenne 2007; Moultnrie et al. 2008; Shapiro and Gebreselassie 2008; Westoff and Cross 2006). A number of hypotheses have been suggested to be behind the stall. For instance, Bongaarts, (2006), Westoff and Cross, (2006) alluded the stall to changes in proximate determinants of fertility. Other authors have suggested lack of progress in socioeconomic determinants to be responsible for the stall (Bongaarts 2008; Shapiro and Gebreselassie 2008). The role of child mortality on fertility stall has also received attention. Westoff and Cross (2006) and Shapiro and Gebreselassie (2008) supported a causal link between increase in infant and child mortality, mainly due to the effect of HIV/AIDS, and fertility stall. The stall in some of the sub-Saharan Africa could also be spurious and might be due to quality of data, however, Kenya is the exception (Schoumaker 2004). Most of these studies have focused on national level data without considering trends by different socio-economic groups.

The role of gender systems on fertility decline has also been recognized in literature (Mason 200 I). The timing and onset of fertility transition in any society is influenced by the prevailing type of gender and family systems. Two separate case studies revealed that that gender relations were important to understand the high fertility in Bungoma located in the former Western province (Jensen and Juma 1989) and the relative low fertility in Kwale located in the former Coast province (Jensen and Khasakhala 1993). In addition, the findings from these case studies indicated a positive association between the experience of child death(s) and high fertility. Child mortality appeared to be an important mechanism that was pushing the fertility up. Despite widespread poverty in both areas, households benefited differently from having many children (Jensen and Juma 1989; Jensen and Khasakhala 1993)

Despite many studies on the dynamics of factors responsible for the Kenyan fertility level, trends and patterns, not much has been done to examine the role of poverty, particularly, in explaining the stall in fertility decline that occurred between 1998 and 2003. It is also unclear, the pathways through which poverty influences fertility in the Kenyan context. The relationship between poverty and fertility is a priority research in many developing countries; however, little attention has been paid to the phenomenon in the Kenyan context. Moreover, there is little agreement on the role of poverty on childbearing at 
the household level. This study is aimed at filling this gap by examining the relationship between household poverty and fertility using successive KDHS from Coast and Western provinces. The study also tests whether the relationship between household poverty and fertility is period and context specific.

\section{Literature Review and Theoretical Framework}

A review of literature on the relationship between poverty and fertility revealed two major streams of work at the micro level. One strand of the extant literature explores the micro-level effects of household economic status on fertility (Amin, Casterline and Spess 2007; Merrick 2002; Montgomery and Hewett 2005). The other strand of literature focuses on the reverse causality, that is, micro-level effects of childbearing on economic wellbeing and poverty (Greene and Merrick 2005). Existing research on the relationship between poverty and fertility in developing countries are based mainly on cross-sectional data and the findings from these studies indicate that the relationship between poverty and fertility is diverse (Schoumaker and Tabutin 1999). While some studies find the relationship to be positive, others show a weak relationship. However, in many developing countries, the link between poverty and fertility is negative. An inverse J-shaped has also been shown in some studies (Aassve, Kedir and Woldegebrie 2006; Aassve. et al. 2005)

A positive relation in which fertility tends to be high among non-poor households has been shown in some settings. For example, Schoumaker and Tabutin (1999) found a positive association between fertility and poverty in countries with low, medium and high fertility rates during the last quarter of the 20th century. Low reproductive capability is argued to be the main reason for the positive association (Lipiton 1998). Other researchers also argue that, in some settings, the very poor may have low demand for children, leading to a lower fertility (Egerö 1996).

The relationship between poverty and fertility is however negative in most developing countries-that is, women from poor households tend to have many children (Schoumaker and Tabutin, 1999). The negative relationship is attributed to a number of reasons. First, high fertility is considered a rational response to poverty (Becker and Lewis 1973; Lipiton 1998). In this case, the benefits of having children outweigh their costs, leading to high demand for children, hence high fertility. Becker and Lewis (1973) pointed out that it is rational for the poor parents to have large families because children are regarded as a source of wealth, provides household labor and offer old age security. A review of existing micro-level research indicates that poor households tend to demand more children to provide cheap labor, and provide old age security especially where state benefits and pensions are lacking (Aassve et al., 2005). However, as the socio-economic status improves, households tend to desire fewer children through quantity-quality trade-off mechanism as suggested by Becker and Lewis (1973) or by increasing opportunity cost of women's time associated with higher income (Willis 1973).

Another important factor explaining the negative relationship between poverty and fertility is the high infant mortality rate which tends to be stronger in poor households (Lutz 1987). High fertility and high mortality rate are causally linked through various mechanisms. On one hand, high infant mortality tends to increase fertility through mechanisms such as replacement and insurance effects (LeGrand et al. 2003). On the other hand, high infant mortality rate can result in high fertility through physiological processes. Since lactation delays the return of regular ovulation, early infant death can shorten the interval between birth and the next conception, especially in population that does not practice contraception.

In high fertility settings such as rural areas of India and Cameroon, the relationship between poverty and fertility was found to be J-shaped (Noumbissi and Sanderson, 1998). The J-shape pattern implies that fertility rate is lower among poor and high-income households compared to middle-income households (Schoumaker 2004). It is argued that the majority of low-income households are peasant farmers, hence they rely less for cheap labour, whereas affluent households have lower fertility due to quantityquality trade-offs. On the other hand, the middleincome households are landholding farms that depend on cheap labour, and therefore have a higher demand for child quantity, which explains the apparent inverse J-shape.

Empirical studies have also examined the reverse causality, namely, micro-level effects of fertility on poverty (Arpino and Aassve 2013; Kedir, Aassve and Woldegebriel 2005). Evidence suggests that a reduction in fertility produces a positive impact on the welfare indicators. For example, a randomized trial of contraception provision in Matlab, Bangladesh found that a reduction in the number of children had significant positive effects on the health, earnings, and household assets of women as well as health and earnings of their children (Joshi and Schultz 2007). High fertility reinforces poverty and makes an escape from poverty rather difficult. A study in Indonesia found that, on average, one birth reduced the likelihood of female labour force participation by 20 percent over a three-year period (Canning and Schofield 2007). Canning and his colleague argued 
that a decline in women's contribution to household income implies a reduction in expenditure per capita in the household. Consequently, a significant number of families enter into poverty while making escape from poverty more difficult and less likely. Moreover, poor households do not necessarily have a higher rate of fertility, but those with higher fertility tend to have a higher rate of entering into poverty and a lower rate of exiting poverty (Aassve et al., 2006).

Arguments on the relationship between poverty and fertility are mainly based on the economics, that is, perceived costs and benefits of children, however, understanding the linkages between poverty and fertility cannot neglect the institutional settings. Economic forces, social organizations and cultural patterns strongly influence prices that determine costs and benefits of children (McNicoll 1980). Thus, the relationship between poverty and fertility depends on social and institutional characteristics. While economic approaches consider high fertility as a rational response to poverty, new evidence has shown the possibility of poverty induced fertility transition (Egerö 1996; Gurmu and Mace 2008). Fertility decline in the absence of any remarkable change in the socio-economic status is mainly attributed to independent effect of family planning programmes (Cleland et al. 1994). Evidence shows that fertility has declined in a number of developing countries like Thailand, Bangladesh, and Nepal, parts of sub-Saharan Africa and Latin America amid unfavorable economic conditions (Cleland et al. 1994; Gurmu and Mace 2008; Kabeer 200 I).

\section{Data and Methods \\ Data}

The study is based on data from the 1989 1993, 1998, 2003, and 2008/9 Kenya Demographic and Health Surveys (KDHS). The KDHS datasets are deemed to be of high quality and are particularly useful in studying the relationship between poverty and fertility over a period of fertility transition due to its standardized sampling, and data collection methodologies. KDHS are nationally representative surveys and are stratified based on the regions (provinces).

\section{Measures}

Two variables are key to this study; household poverty and fertility. The latter is the dependent variable while the former is the main independent variable. Since the DHS does not collect information on income and expenditure, researchers often rely on wealth index as a proxy measure of household poverty. The index is based on possession of assets and household amenities (Filmer and Pritchett 200I).
Wealth index is computed using principal component analysis methods using binary variables measuring the availability of household assets (such as television, motor car, and bicycle), materials used to construct household walls, roof and household amenities such as type of toilet and main source of drinking water. The quintiles are then developed by categorizing the population into five equal parts, ranging from the poorest to the wealthiest households (Rutstein and Johnson. 2004). For the present analysis, wealth index was used to measure household poverty.

The classical poverty measurement usually characterized a given population into poor and nonpoor based on a given cut-off point. Following the same procedure, this study re-categorized household wealth index quintiles into three groups. The lowest 40 percent (first and second wealth quintiles) constitute the poor, the next 20 percent (third quintile) represents the middle and the last 40 percent (fourth and fifth quintiles) represents the wealthiest (non-poor). We assume that the lowest 40 percent is well within the poverty cut-off point and can best represent the poor since we do not have a poverty line for the areas being studied. A similar approach has been used before to study the effects of poverty on childbearing in 47 countries (Amin et al. 2007). As with any poverty measure, the cut-off point between poor and non-poor remains unclear (Qizilbash and Clark 2005).

The DHS collects information on birth histories or maternity histories retrospectively which are an indispensable source of information for studying fertility levels and trends. In this study, two fertility measures were used. First, periodic measures of fertility - that is age-specific fertility rate (ASFR) and total fertility rate (TFR). Age-specific fertility rates are calculated for five or four-year periods preceding the interview and are calculated by restricting numerator to births occurring to women of a specified age interval. The denominator is restricted to the number of person-years lived by women in the age interval (Preston et al., 200I). TFR is the sum of ASFR multiplied by 5 . Both the ASFR and TFRs are computed for all women aged 15-49. Second, the study used the number of children born in the last five years preceding the survey. Literature suggests two possible ways of capturing fertility at the microlevel: the actual reproduction experience of women or couple and the fertility preferences on the number of children (Farooq, 1985). Two main reasons informed the choice of period ( 5 year preceding the survey). First, the widespread fertility decline accompanied by shifting fertility differentials favors a short period of observation (Rodriguez and Cleland 198I). Second, the choice of five-year preceding the survey is preferable when the sample smaller sample 
size is small and when the objective is to analyze fertility differentials during a recent period (Cleland and Kaufmann 1998; Schoumaker 20II). Examining births over a shorter period could also help minimize endogeneity issues (Bollen, Glanville and Stecklos 2007).

Household wealth, education level, and experience of under-five mortality are used as socioeconomic factors, while type of marital union is used as a control of socio-cultural factor. Contraceptive use, partner's approval of family planning and spousal communication on family planning (FP) are included to control for diffusion/psychological factors. Age of the woman in continuous and quadratic form was used as a control in all the estimated models. All of the categorical explanatory variables were first converted into dummy variables before being included in the equation.

\section{Statistical analysis}

The analysis adopted two approaches. First, the study used Poisson regression to compute fertility rates and rate ratios by applying a new Stata command -tfr2 (Schoumaker 2013). This approach uses the person's period data as obtained from birth history data and divides the period over which rates are to be calculated into several sub periods or segments over the course of which the explanatory variables remain constant (detailed explanation can be read in Schoumaker, 20/3). Two models were fitted for Coast and Western provinces. The first model involved running the model with household wealth status as explanatory variables, while the second model included level of education and child mortality. The inclusion of these two variables was informed by literature which indicates that the high fertility in subSaharan Africa is mainly due to the persistent high levels of child mortality and low levels of maternal education (Bongaarts, 2008).

In the interpretation, the exponentials of the coefficients measure rate ratios, e.g. the exponential of the coefficient for the non-poor women measures the ratio of the TFR of these women to the TFR of the poor women, taken as the reference category. The rate ratios estimate how much of the relative difference in the total fertility rate between the poor and non-poor women. The rates are computed for the five years preceding the survey.

The second approach ran a Poisson model in which the number of births in the last five years preceding the survey was used as the outcome variable and household wealth as the main predictor variable. Analysis was based on currently married women due to the inclusion of the following independent variables-type of union, partner's approval of family planning and spousal communication on family planning. The number of births in the last five years is a count event and it is assumed to occur randomly to each woman. Hence, Poisson modeling is preferred (Rodriguez and Cleland 1988; Winkelmann and Zimmermann 1994).

\section{Poisson Model Specification}

$$
\begin{aligned}
\operatorname{Pr}(Y= & y)=\frac{e^{-\lambda h}(\lambda h)^{y}}{y !} \lambda>0 \text { andy } \\
& =0,1, \ldots \ldots \ldots \ldots \ldots \ldots \ldots \ldots \ldots \ldots, n
\end{aligned}
$$

Where, $Y$ is a random variable indicating the number of occurrence of an event; $\lambda$ is the rate of occurrence of the event per unit time, and $h$ is the length of time during which the event is being recorded. If the probability that the random variable $Y_{i}$ is equal to $y_{i}$ is assumed to follow a Poisson distribution with mean $\mu_{i}$, then,

$$
\left(P\left(Y_{i}=\frac{y_{i}}{\mu_{i}}\right)=\frac{e^{-\mu_{i}} * \mu_{i}^{y_{i}}}{y_{i}}\right.
$$

By introducing regressors, $\mu_{i}$ is specified conventionally as $\mu_{i}=\exp \left(\beta_{0}+\sum \beta_{k} \chi_{k i}\right)$. Where, $\mu_{i}$ is the expected number of children per woman I; $\beta_{0}$ is the intercept; $B_{j s}$ are regression coefficients; and $X_{i s}$ are explanatory variables.

The aim is to estimate and compare results of each survey year based on two models. The first model (I) examines the effects of socioeconomic factors, viz. household wealth status, level of education and child mortality. In the second model (II), cultural factor (type of union), and diffusion/psychological factors (contraceptive use, partner's approval of family planning and spousal communication on family planning) were included as controls. Age of the woman in continuous and quadratic form is used as a control in all the estimated models because of suspected non-linear relationship between ages as a variable and fertility.

\section{Results}

Table I presents the distribution of women aged 1549 according to selected background characteristics: age, household wealth level of education and marital status. Information is based on the 1989, 1993, 1998, 2003, and 2008/2009 Kenya Demographic and Health Surveys (KDHS) for Coast and Western provinces. There was no significant variation in the distribution of respondents by background characteristic across the years in both Coast and Western province. 
Table I: Percentage distribution of women aged I5-49 by selected background characteristics: Coast and Western provinces 1989-2008/9 KDHS

\begin{tabular}{|c|c|c|c|c|c|}
\hline \multicolumn{6}{|c|}{ Coast Province } \\
\hline & 1989 & 1993 & 1998 & 2003 & $2008 / 9$ \\
\hline \multicolumn{6}{|l|}{ Age } \\
\hline $15-24$ & 35.2 & 45.8 & 42.4 & 40.7 & 42.4 \\
\hline $25-34$ & 35.4 & 31.2 & 28.6 & 34.0 & 31.4 \\
\hline $35-49$ & 29.5 & 22.9 & 29.0 & 25.2 & 26.2 \\
\hline \multicolumn{6}{|l|}{ Household Wealth } \\
\hline Poor & 36.1 & 37.1 & 27.7 & 33.0 & 36.3 \\
\hline Middle & 22.5 & 12.2 & 20.3 & 14.7 & 12.1 \\
\hline Non-poor & 41.4 & 50.7 & 52 & 52.2 & 51.6 \\
\hline \multicolumn{6}{|l|}{ Education } \\
\hline No education & 52.2 & 28.6 & 28.3 & 28.5 & 22.7 \\
\hline Primary & 33.3 & 49.8 & 47.5 & 50.2 & 51.9 \\
\hline Secondary & 14.4 & 21.6 & 24.2 & 21.3 & 25.4 \\
\hline \multicolumn{6}{|l|}{ Marital status } \\
\hline Never married & 22.3 & 29.0 & 29.1 & 31.2 & 30.7 \\
\hline Currently married & 72.5 & 64.7 & 64.7 & 59.9 & 58.0 \\
\hline Formerly married & 5.2 & 6.3 & 6.1 & 8.9 & 11.3 \\
\hline $\mathbf{N}$ & 1027 & 945 & 896 & 991 & 1039 \\
\hline \multicolumn{6}{|c|}{ Western Province } \\
\hline \multicolumn{6}{|l|}{ Age } \\
\hline $15-24$ & 41.1 & 47.1 & 43.9 & 48.0 & 44.4 \\
\hline $25-34$ & 32.9 & 26.7 & 28.2 & 26.8 & 28.5 \\
\hline $35-49$ & 25.9 & 26.1 & 27.8 & 25.2 & 27.1 \\
\hline \multicolumn{6}{|l|}{ Household Wealth } \\
\hline Poor & 47.4 & 54.7 & 47.2 & 45.0 & 44.3 \\
\hline Middle & 24.5 & 20.5 & 25.8 & 24.9 & 21.9 \\
\hline Non-poor & 28.0 & 24.8 & 27.0 & 30.1 & 33.8 \\
\hline \multicolumn{6}{|l|}{ Education } \\
\hline No education & 21.7 & 12.9 & 10.3 & 8.3 & 4.7 \\
\hline Primary & 56.0 & 60.7 & 58.0 & 63.7 & 66.6 \\
\hline Secondary & 22.3 & 26.3 & 31.7 & 28.1 & 28.7 \\
\hline \multicolumn{6}{|l|}{ Marital status } \\
\hline Never married & 17.5 & 30.4 & 27.2 & 25.1 & 27.2 \\
\hline Currently married & 73.5 & 59.7 & 61.4 & 61.3 & 62.5 \\
\hline Formerly married & 9.0 & 9.9 & 11.4 & 13.6 & 10.4 \\
\hline $\mathbf{N}$ & 720 & 1091 & 1226 & 938 & 1149 \\
\hline
\end{tabular}

Source: Computed by researcher from KDHS 1989-2008/9 
Table 2 shows trends in the relationships between household wealth status and fertility in Coast and Western provinces. Age-specific fertility rates and TFRs are computed for the reference category poor households - and rate ratios are displayed for the middle and non-poor categories of household wealth. In Coast province, TFR of non-poor women was $0.65,0.70$ and 0.76 times lower than that of poor women in 1989, 1993 and 1998 respectively. The trend reversed dramatically since 1998 as fertility among poor women increased. The fertility rate of non-poor women was 0.53 and 0.49 times lower than poor women in 2003 and 2008/9 respectively. The differentials by household wealth between the poor and non-poor categories were found to be statistically significant at the $\mathrm{p}<0.0 \mathrm{l}$ level. An important observation is that the fertility among poor women was above five children in all the surveys.

In Western province, results indicate a fairly different pattern in terms of fertility rates among poor women. The magnitude in the difference between fertility of poor women and non-poor women has been increasing over the years. Although fertility declined among poor and non-poor women, the decline was greater among non-poor women, thus widening the gap. TFR of non-poor women was $0.78,0.75$ and 0.72 times lower than the TFR of poor women in 1989, 1993 and 1998 respectively. However, there was a reversal in the decline between 2003 and 2008/9 when fertility among nonpoor women was 0.67 times that of poor women. These differentials were also found to be statistically significant at the $p<0.0$ l level.

Tables 3 present the results of the second model. The differential effects of household wealth remain significant although it is slightly attenuated after including level of education and experience of child mortality. This indicates that other factors explain the differential effect of household wealth on fertility. Major differences between Coast and Western provinces are prominent in the second model. In Coast province, the effect of education was significant except in 1989 and is becoming more important in each survey. In contrast, the effect of education in Western province was weak and diminished over the years. In both provinces, the effect of death of a child under five was consistent and significant in all the periods. 
African Population Studies Vol. 29, No. 2, 2015

Table2: Trends in fertility rates and rate ratios by household wealth for the 5 years preceding the Survey for Coast and Western provinces

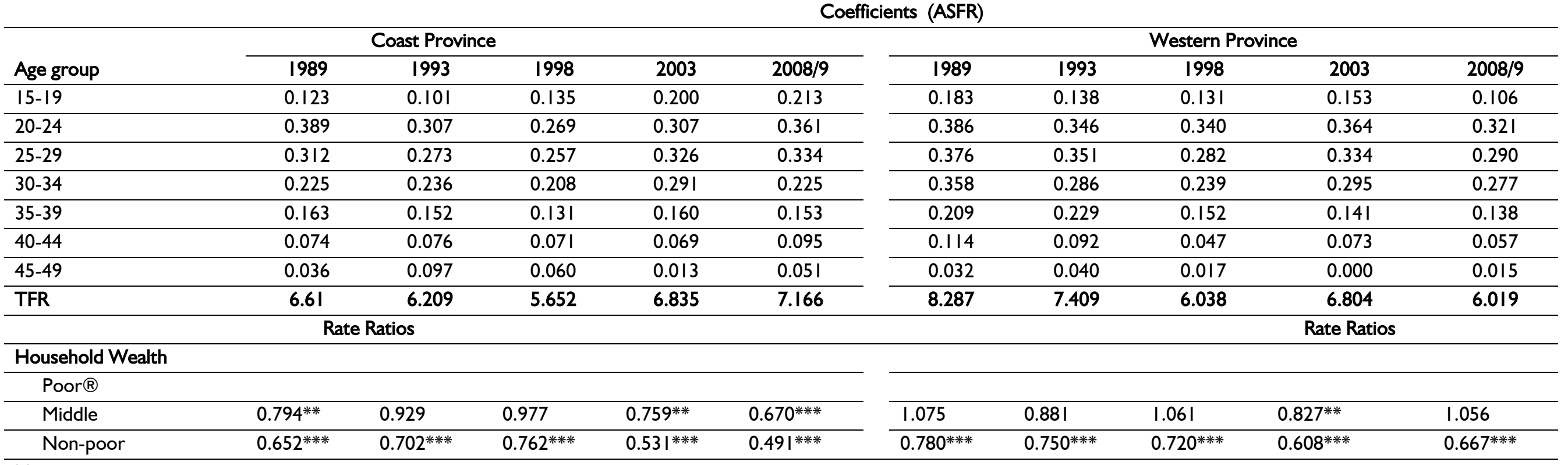

Notes

I. Computation done with tfr2 syntax

2. ASFRs and TFR for the reference category/ies (categorical covariate) or covariate/s equal to 0

3. Rate ratios of explanatory variables - Assumption of constant age fertility schedule

4. Legend: * $\mathrm{p}<. \mathrm{I}$; ** $\mathrm{p}<.05$; *** $\mathrm{p}<.0$ I

5. $®$-Reference category

Source: Computed by researcher from KDHS 1989-2008/9. 
Table 3: Trends in fertility rates and rate ratios by household wealth controlling for education and child mortality for Coast and Western provinces

\begin{tabular}{|c|c|c|c|c|c|c|c|c|c|c|}
\hline \multirow[b]{3}{*}{ Age group } & \multicolumn{10}{|c|}{ Coefficients (ASFR) } \\
\hline & \multicolumn{5}{|c|}{ Coast Province } & \multicolumn{5}{|c|}{ Western Province } \\
\hline & 1989 & 1993 & 1998 & 2003 & $2008 / 9$ & 1989 & 1993 & 1998 & 2003 & $2008 / 9$ \\
\hline $15-19$ & 0.108 & 0.102 & 0.141 & 0.204 & 0.242 & 0.190 & 0.112 & 0.143 & 0.137 & 0.094 \\
\hline $20-24$ & 0.328 & 0.296 & 0.265 & 0.307 & 0.379 & 0.376 & 0.263 & 0.356 & 0.298 & 0.262 \\
\hline $25-29$ & 0.253 & 0.256 & 0.247 & 0.311 & 0.348 & 0.340 & 0.259 & 0.274 & 0.264 & 0.227 \\
\hline $30-34$ & 0.172 & 0.207 & 0.191 & 0.257 & 0.227 & 0.306 & 0.196 & 0.219 & 0.222 & 0.203 \\
\hline $35-39$ & 0.129 & 0.130 & 0.109 & 0.140 & 0.148 & 0.174 & 0.157 & 0.134 & 0.104 & 0.096 \\
\hline $45-49$ & 0.027 & 0.083 & 0.045 & 0.010 & 0.044 & 0.026 & 0.026 & 0.014 & 0.000 & 0.010 \\
\hline \multirow[t]{2}{*}{ TFR } & 5.369 & 5.700 & 5.274 & 6.433 & 7.369 & 7.507 & 5.37 & 5.902 & 5.396 & 4.647 \\
\hline & Rate Ratios & & & & & & & Rate Ratio & & \\
\hline \multicolumn{11}{|l|}{ Household Wealth } \\
\hline \multicolumn{11}{|l|}{ Poor $\AA$} \\
\hline Middle & 0.806* & 0.9242 & 1.001 & 0.859 & $0.770 * *$ & $1.117 *$ & 0.897 & 1.078 & $0.8455^{* *}$ & 1.0867 \\
\hline Non-poor & $0.664 * * *$ & $0.796 * * *$ & 0.868 & $0.645^{* * * *}$ & $0.719 * * *$ & 0.908 & $0.793 * * *$ & $0.809 * *$ & $0.689 * * *$ & $0.783 * *$ \\
\hline \multicolumn{11}{|l|}{ Level of education } \\
\hline \multicolumn{11}{|l|}{ No education ${ }^{\circledR}$} \\
\hline Primary & 1.164 & 1.004 & 0.876 & 0.874 & $0.763 * * *$ & 0.918 & 1.165 & 0.889 & 1.085 & 1.111 \\
\hline Secondary and above & 1.039 & $0.690 * * *$ & $0.734^{* * * *}$ & $0.604 * * *$ & $0.4 I I * * *$ & $0.76 I^{* * * *}$ & 1.079 & $0.783 *$ & 0.919 & 0.906 \\
\hline \multicolumn{11}{|l|}{ Experienced Child death } \\
\hline \multicolumn{11}{|l|}{$\mathrm{No} \circledast$} \\
\hline Yes & $\mathrm{I} .407^{* * * *}$ & $1.256 * * *$ & $\mathrm{I} .487^{* * *}$ & I.384*** & I.309*** & I.397*** & $1.614 * * *$ & I.442*** & $1.545 * * *$ & $1.553 * * *$ \\
\hline \multicolumn{11}{|l|}{ Notes } \\
\hline \multicolumn{11}{|c|}{ I. Computation done with tfr2 syntax } \\
\hline \multicolumn{11}{|c|}{ 2. ASFRs and TFR for the reference category/ies (categorical covariate) or covariate/s equal to 0} \\
\hline \multicolumn{11}{|c|}{ 3. Rate ratios of explanatory variables - Assumption of constant age fertility schedule } \\
\hline $\begin{array}{l}\text { 4. Legend: } * p<. I \text {; } \\
\text { ( } \text {-Reference } \mathrm{Ca}\end{array}$ & ;*** $\mathrm{p}<.0 \mathrm{I}$ & & & & & & & & & \\
\hline
\end{tabular}


Tables 4 and 5 show results of the Poisson regression in which the number of births in the last five years is the dependent variable. The results from all the five KDHS surveys were compared for Coast and Western provinces to show the extent to which the effect of household wealth has changed. Consistent with the result shown earlier in Tables 2, the unadjusted effect of household wealth on fertility was negative and statistically significant at $(p<0.000)$ in both areas ${ }^{2}$.

Household wealth has a significant negative effect on fertility among currently married women in Coast province across all the KDHS. Model I shows that births in the last five-year period among currently married women decreased with the level of household wealth across all surveys. Fertility rate of non-poor women relative to poor women was about 0.78 times, 0.87 times, and 0.85 times lower in 1989, 1993 and 1998, respectively. The influence of household wealth was higher in 2003 and 2008/9 as the magnitude of the difference between poor and non-poor women increased. Results also indicate that the fertility of non-poor women relative to poor women was 0.71 times and 0.69 times lower in 2003 and 2008/9 respectively. Controlling for cultural and psychological factors, Model II indicates that household wealth still remained significant with a slightly increased magnitude in its effect on fertility.

Education was found to be an important determinant of fertility among married women in Coast province although the results were only significant in 2003 and 2008/9. In Model I, the role of education was eminent in 2003 and 2008/9. The fertility rate of married women with secondary education was 0.76 times and 0.74 times lower in 2003 and 2008/9, respectively. Model II shows that, fertility rate of women with secondary or higher education was $0.7 \mathrm{I}$ times, 0.90 times, $0.8 \mathrm{I}$ times and 0.72 times lower than fertility rate of women with no education in 1993, 1998, 2003 and 2008/9, respectively, when all other factors are controlled.

Child mortality had a significant positive effect on fertility throughout the survey. Results from Model I show that the fertility rate of women who had experienced any death of a child under five was 1.34 times, I.22 times, I.48 times and higher than women who had not lost a child under five years in 1989, 1993 and 1998, respectively. The important role played by child mortality becomes much clearer after controlling for other factors.

In Western province, the results in model I show that the household wealth was negative and insignificant during earlier periods (1989-1998). However, between 2003 and 2008/9, household wealth had a significant effect. Thus, the impact of poverty was stronger during the period of the fertility stall (1998-2008/9. Result shows that the fertility rate of non-poor women was 0.76 times and 0.68 times lower than poor women in 2003 and 2008/9 respectively. However, the results in model II did not show any changes in the relationship between household wealth and fertility after controlling for other covariates. In terms of educational attainment, results show that education is not an important determinant of fertility for in Western province; although there is an inverse relationship between the level of education and fertility. This implies that the fertility transition in Western province is mainly driven by other factors other than education. Alternatively, the effect of education on fertility could be latent and occurring indirectly through other factors. Similar to Coast province, results indicate that child mortality has a significant positive effect on fertility throughout the study period $(p<0.000)$.

\footnotetext{
${ }^{2}$ Results are not shown here and can be made available upon request
} 
Table 4: Parameter estimates for Poisson regression model of recent fertility among married women: Coast province 1989-2008/9

\begin{tabular}{|c|c|c|c|c|c|c|c|c|c|c|c|c|}
\hline & \multicolumn{4}{|c|}{1989} & \multicolumn{4}{|c|}{1993} & \multicolumn{4}{|c|}{1998} \\
\hline & \multicolumn{2}{|c|}{ Model I } & \multicolumn{2}{|c|}{ Model II } & \multicolumn{2}{|c|}{ Model I } & \multicolumn{2}{|c|}{ Model II } & \multicolumn{2}{|c|}{ Model I } & \multicolumn{2}{|c|}{ Model II } \\
\hline & IRR & $P>z$ & IRR & $P>z$ & IRR & $P>z$ & IRR & $P>z$ & IRR & $P>z$ & IRR & $P>z$ \\
\hline \multicolumn{13}{|l|}{ Household Wealth } \\
\hline Middle & 0.865 & 0.191 & 0.828 & 0.094 & 0.832 & 0.130 & 0.777 & 0.043 & 0.937 & 0.538 & 0.954 & 0.657 \\
\hline Non-poor & 0.782 & 0.031 & 0.715 & 0.006 & 0.868 & 0.122 & 0.815 & 0.035 & 0.853 & 0.095 & 0.842 & 0.077 \\
\hline \multicolumn{13}{|l|}{ Education } \\
\hline \multicolumn{13}{|c|}{ No education ${ }^{\circledR}$} \\
\hline Primary & $\mathrm{I} .148$ & 0.211 & 1.048 & 0.682 & 0.962 & 0.667 & 0.867 & 0.143 & 1.011 & 0.907 & 0.943 & 0.536 \\
\hline Secondary + & $\mathrm{I} .177$ & 0.290 & 1.033 & 0.839 & 0.845 & 0.193 & 0.722 & 0.018 & 0.973 & 0.815 & 0.903 & 0.409 \\
\hline \multicolumn{13}{|c|}{ Experienced Child death } \\
\hline \multicolumn{13}{|l|}{$\mathrm{No} \otimes$} \\
\hline Yes & 1.338 & 0.002 & 1.342 & 0.002 & 1.218 & 0.025 & 1.242 & 0.018 & 1.480 & 0.000 & 1.454 & 0.000 \\
\hline \multicolumn{13}{|l|}{ Type of union } \\
\hline \multicolumn{13}{|l|}{ Polygamy ${ }^{\circledR}$} \\
\hline Monogamy & & & 0.939 & 0.513 & & & 0.787 & 0.025 & & & 1.097 & 0.346 \\
\hline Disapproves & & & 0.900 & 0.453 & & & 0.955 & 0.686 & & & 0.956 & 0.651 \\
\hline Don't Know & & & 1.047 & 0.755 & & & 1.018 & 0.894 & & & 0.899 & 0.425 \\
\hline \multicolumn{13}{|c|}{ Spousal communication on FP } \\
\hline \multicolumn{13}{|c|}{ Never Discussed $^{\circledR}$} \\
\hline Discussed & & & 1.396 & 0.023 & & & I.24I & 0.049 & & & $\mathrm{I} .354$ & 0.015 \\
\hline \multicolumn{13}{|c|}{ Contraceptives Use } \\
\hline \multicolumn{13}{|l|}{ Never Use ${ }^{\circledR}$} \\
\hline Ever Use & & & 1.114 & 0.380 & & & $\mathrm{I} .148$ & 0.153 & & & 0.994 & 0.951 \\
\hline \multicolumn{13}{|l|}{ Age } \\
\hline Age Squared & $\mathrm{I} .28 \mathrm{I}$ & 0.000 & 1.258 & 0.000 & 1.276 & 0.000 & $\mathrm{I} .227$ & 0.000 & 1.295 & 0.000 & 1.264 & 0.000 \\
\hline Pseudo $\mathrm{R}^{2}$ & 0.995 & 0.000 & 0.996 & 0.000 & 0.995 & 0.000 & 0.996 & 0.000 & 0.995 & 0.000 & 0.996 & 0.000 \\
\hline $\mathbf{N}$ & & 529 & & 527 & & 651 & & 621 & & 753 & & 749 \\
\hline
\end{tabular}




\section{Table 4 Continued}

\begin{tabular}{|c|c|c|c|c|c|c|c|c|}
\hline & \multicolumn{4}{|c|}{2003} & \multicolumn{4}{|c|}{$2008 / 9$} \\
\hline & \multicolumn{2}{|c|}{ Model I } & \multicolumn{2}{|c|}{ Model II } & \multicolumn{2}{|c|}{ Model I } & \multicolumn{2}{|c|}{ Model II } \\
\hline & IRR & $P>z$ & IRR & $P>z$ & IRR & $\mathbf{P}>\mathbf{z}$ & IRR & $P>z$ \\
\hline \multicolumn{9}{|l|}{ Household Wealth } \\
\hline Middle & 0.844 & 0.182 & 0.832 & 0.166 & 0.717 & 0.011 & 0.706 & 0.009 \\
\hline Non-poor & 0.708 & 0.001 & 0.725 & 0.002 & 0.685 & 0.000 & 0.666 & 0.000 \\
\hline \multicolumn{9}{|l|}{ Education } \\
\hline \multicolumn{9}{|l|}{ No education $\AA$} \\
\hline Primary & 0.904 & 0.282 & 0.9 & 0.29 & 0.899 & 0.219 & 0.849 & 0.067 \\
\hline Secondary + & 0.759 & 0.073 & 0.813 & 0.206 & 0.744 & 0.030 & 0.715 & 0.015 \\
\hline \multicolumn{9}{|l|}{ Experience of U5 death } \\
\hline \multicolumn{9}{|l|}{$\mathrm{No} \otimes$} \\
\hline Yes & 1.335 & 0.002 & 1.281 & 0.010 & 1.209 & 0.027 & 1.237 & 0.016 \\
\hline \multicolumn{9}{|l|}{ Type of union } \\
\hline \multicolumn{9}{|l|}{ Polygamy $^{\circledR}$} \\
\hline Monogamy & & & 0.947 & 0.608 & & & 0. & 0.287 \\
\hline \multicolumn{9}{|l|}{ Approves $^{\circledR}$} \\
\hline Disapproves & & & 0.804 & 0.054 & & & 1.005 & 0.980 \\
\hline Don't Know & & & 0.919 & 0.49 & & & 1.201 & 0.631 \\
\hline \multicolumn{9}{|l|}{ Spousal comm. on FP } \\
\hline \multicolumn{9}{|l|}{ Never Discussed $^{\circledR}$} \\
\hline Discussed & & & 1.227 & 0.062 & & & 1.348 & 0.252 \\
\hline \multicolumn{9}{|l|}{ Contraceptives Use } \\
\hline \multicolumn{9}{|l|}{ Never Use ${ }^{\circledR}$} \\
\hline Ever Use & & & 0.862 & 0.197 & & & 1.169 & 0.054 \\
\hline Age & 1.283 & 0.000 & 1.291 & 0.000 & & & 1.232 & 0.000 \\
\hline Age Squared & 0.995 & 0.000 & 0.995 & 0.000 & 1.256 & 0.000 & 0.996 & 0.000 \\
\hline Pseudo $R^{2}$ & & 0.093 & & 0.101 & 0.996 & 0.000 & & 0.094 \\
\hline $\mathbf{N}$ & & 575 & & 564 & & 718 & & 697 \\
\hline
\end{tabular}


Table 5: Table 4: Parameter estimates for Poisson regression model of recent fertility among married women: Western province 1989-2008/9

\begin{tabular}{|c|c|c|c|c|c|c|c|c|c|c|c|c|}
\hline & \multicolumn{4}{|c|}{1989} & \multicolumn{4}{|c|}{1993} & \multicolumn{4}{|c|}{1998} \\
\hline & \multicolumn{2}{|c|}{ Model I } & \multicolumn{2}{|c|}{ Model II } & \multicolumn{2}{|c|}{ Model I } & \multicolumn{2}{|c|}{ Model II } & \multicolumn{2}{|c|}{ Model I } & \multicolumn{2}{|c|}{ Model II } \\
\hline & IRR & $P>z$ & IRR & $P>z$ & IRR & $P>z$ & IRR & $P>z$ & IRR & $P>z$ & IRR & $P>z$ \\
\hline \multicolumn{13}{|l|}{ Household Wealth } \\
\hline Middle & 1.035 & 0.624 & 1.020 & 0.787 & 0.920 & 0.386 & 0.924 & 0.419 & 1.016 & 0.856 & 1.004 & 0.961 \\
\hline Non-poor & 0.910 & 0.265 & 0.896 & 0.206 & 0.869 & 0.146 & 0.857 & 0.123 & 0.898 & 0.306 & 0.897 & 0.311 \\
\hline \multicolumn{13}{|l|}{ Education } \\
\hline \multicolumn{13}{|c|}{ No education $\AA$} \\
\hline Primary & 0.962 & 0.606 & 0.950 & 0.501 & 1.094 & $0.4 I 4$ & $1.04 \mathrm{I}$ & 0.730 & 0.835 & 0.217 & 0.856 & 0.290 \\
\hline Secondary + & 0.857 & 0.127 & 0.842 & 0.095 & 1.098 & 0.468 & 0.995 & 0.970 & 0.844 & 0.273 & 0.875 & 0.400 \\
\hline \multicolumn{13}{|c|}{ Experience of U5 death } \\
\hline \multicolumn{13}{|l|}{$\mathrm{No} \circledast$} \\
\hline Yes & 1.300 & 0.000 & $\mathrm{I} .282$ & 0.000 & 1.389 & 0.000 & 1.430 & 0.000 & 1.310 & 0.001 & 1.299 & 0.002 \\
\hline \multicolumn{13}{|l|}{ Type of union } \\
\hline \multicolumn{13}{|l|}{ Polygamy ${ }^{\circledR}$} \\
\hline Monogamy & & & 0.998 & 0.974 & & & 0.978 & 0.801 & & & 0.811 & 0.077 \\
\hline Disapproves & & & 0.947 & 0.464 & & & 0.918 & 0.345 & & & 0.920 & 0.372 \\
\hline Don't Know & & & 0.931 & 0.465 & & & 0.901 & 0.436 & & & 0.884 & 0.480 \\
\hline \multicolumn{13}{|c|}{ Spousal communication on FP } \\
\hline \multicolumn{13}{|c|}{ Never Discussed $^{\circledR}$} \\
\hline Discussed & & & 1.191 & 0.032 & & & 1.469 & 0.000 & & & 1.061 & 0.642 \\
\hline \multicolumn{13}{|l|}{ Contraceptives Use } \\
\hline \multicolumn{13}{|l|}{ Never Use ${ }^{\circledR}$} \\
\hline Ever Use & & & 0.965 & 0.653 & & & 0.960 & 0.605 & & & 0.914 & 0.266 \\
\hline Age & 1.376 & 0.000 & $\mathrm{I} .367$ & 0.000 & 1.356 & 0.000 & 1.335 & 0.000 & 1.370 & 0.000 & 1.370 & 0.000 \\
\hline Age Squared & 0.994 & 0.000 & 0.994 & 0.000 & 0.995 & 0.000 & 0.995 & 0.000 & 0.994 & 0.000 & 0.994 & 0.000 \\
\hline Pseudo $\mathbf{R}^{2}$ & & 0.087 & & 0.091 & & 0.082 & & 0.096 & & 0.106 & & 0.107 \\
\hline $\mathbf{N}$ & & 745 & & & & 611 & & & & 578 & & \\
\hline
\end{tabular}




\section{Table 5 Continued}

\begin{tabular}{|c|c|c|c|c|c|c|c|c|}
\hline & IRR & $P>z$ & IRR & $P>z$ & IRR & $P>z$ & IRR & $P>z$ \\
\hline \multicolumn{9}{|l|}{ Household Wealth } \\
\hline \multicolumn{9}{|l|}{ Poor $^{\circledR}$} \\
\hline Middle & 0.907 & 0.283 & 0.916 & 0.336 & 0.995 & 0.961 & 0.986 & 0.887 \\
\hline Non-poor & 0.758 & 0.007 & 0.768 & 0.012 & 0.667 & 0.000 & 0.668 & 0.000 \\
\hline \multicolumn{9}{|l|}{ Education } \\
\hline \multicolumn{9}{|l|}{ No education ${ }^{\circledR}$} \\
\hline Primary & 1.118 & 0.467 & 1.096 & 0.551 & 1.101 & 0.677 & 1.093 & 0.704 \\
\hline Secondary + & 1.086 & 0.635 & 1.042 & 0.814 & 0.997 & 0.989 & 0.984 & 0.946 \\
\hline \multicolumn{9}{|c|}{ Experience of U5 death } \\
\hline \multicolumn{9}{|l|}{$\mathrm{No} \circledast$} \\
\hline Yes & 1.382 & 0.000 & 1.402 & 0.000 & 1.352 & 0.001 & $\mathrm{I} .344$ & 0.001 \\
\hline \multicolumn{9}{|l|}{ Type of union } \\
\hline \multicolumn{9}{|l|}{ Polygamy ${ }^{\circledR}$} \\
\hline Monogamy & & & 0.861 & 0.139 & & & 1.046 & 0.660 \\
\hline \multicolumn{9}{|c|}{ Partner Approval of FP } \\
\hline \multicolumn{9}{|l|}{ Approves $^{\circledR}$} \\
\hline Disapproves & & & 0.893 & 0.208 & & & 0.995 & 0.974 \\
\hline Don't Know & & & 0.897 & 0.515 & & & 0.906 & 0.794 \\
\hline \multicolumn{9}{|c|}{ Spousal communication on FP } \\
\hline \multicolumn{9}{|l|}{ Never Discussed ${ }^{\circledR}$} \\
\hline Discussed & & & $\mathrm{I} .388$ & 0.001 & & & $\mathrm{I} .054$ & 0.749 \\
\hline \multicolumn{9}{|l|}{ Contraceptives Use } \\
\hline \multicolumn{9}{|l|}{ Never Use ${ }^{\circledR}$} \\
\hline Ever Use & & & 0.959 & 0.600 & & & 1.017 & 0.849 \\
\hline Age & 1.326 & 0.000 & 1.311 & 0.000 & 1.320 & 0.000 & 1.321 & 0.000 \\
\hline Age Squared & 0.995 & 0.000 & 0.995 & 0.000 & 0.995 & 0.000 & 0.995 & 0.000 \\
\hline Pseudo $\mathrm{R}^{2}$ & & 0.121 & & 0.131 & & 0.116 & & 0.118 \\
\hline $\mathbf{N}$ & & 594 & & & & 603 & & \\
\hline
\end{tabular}




\section{Discussion}

The study examined the relationship between household poverty and fertility and tested whether this relationship depends on the period and context. The study used successive KDHS dataset of 1989 , 1993, 1998, 2003 and 2008/9. Results show existence of fertility differentials by household wealth status in both Coast and Western provinces. Overall, the TFR of poor women is high across all the surveys in both regions. Two patterns are observed. First, the magnitude of the difference in TFR between poor and non-poor women declined during the period 1989-1998. Second, there was a stall in fertility decline between 1998-2008/9, a period during which the gap between the TFR of poor and non-poor women widened. The increase of the gap was mainly attributed to increase in fertility rate among poor women. The relationship between household wealth and fertility over the period of the fertility transition shows distinct patterns. In Coast province, fertility rate among poor household displayed a U-shaped pattern. The total fertility rate of poor women declined from 6.6 children per woman in 1989 to 5.6 children per woman in 1998 then increased drastically to 6.8 children per woman in 2003 and 7.2 children per woman in 2008/9. Overall, the fertility rate among poor women increased by 15 percent over the period under study. In contrast, fertility rate among poor household in Western province, indicates an inverted J-shaped pattern. The total fertility rate among poor women initially declined followed by a stall. Fertility rate among poor women in Western province declined by 26 percent from 8.2 children per woman in 1989 to 6.0 children per woman in 2008/9. The role of poverty in the fertility decline is therefore more clearly visible. The results corroborate findings from previous studies by Schoumaker (2004) and Schoumaker and Tabutin, (1999) on the relationship between economic status and fertility.

Furthermore, the differentials in fertility by household wealth status persist even after introducing variables such as level of education and experience of death of a child under-five. However, child mortality seems to significantly push fertility upwards in both study regions. The result suggests that poverty aided by child mortality could be a key factor in the lack of progress in fertility decline in Coast and Western provinces and the cause of the stall in fertility decline. The findings are consistent with the hypothesis that fertility stalls are due to trends in socioeconomic determinants (Bonngaarts, 2008). Arnstein et al. (2005) argued that the persistence of high levels of fertility and poverty is largely driven by lack of economic growth, poor access to family planning, education and healthcare. The debates as to whether poverty contributes to high fertility continue to dominate much of the demographic discourse. Much of the explanation given for the persistently high fertility among the poor revolve around economic paradigm that high fertility is a rational response to poverty (Lipton, 1999). In other words, the benefits of bearing more children outweigh their costs among poor households, leading to high fertility. The main reasons cited to explain high fertility among the poor include old-age security (Nugent and Gillaspy 1983; Srinivasan 1988) and high child mortality (Ben-Porath 1976; Caldwell and Caldwell 1987). The poor tends to have large families since parents believe that children provide economic support during old-age particularly in the context where state benefits and well-developed social security systems are lacking or inadequate.

The result shows that child mortality is the single most important factor influencing fertility rate. The findings support the common argument that fertility is in part determined by the level of child mortality. The causal link between child mortality and fertility can be explained using Lutz's (1987) framework in which poor households are not able to provide quality childcare to the new born hence resulting to higher mortality. Higher mortality among the poor households in turn make parents to increase their fertility through various mechanisms, such as replacement and insurance effects (Schultz (198I; Schoumaker, 2004).

The study findings have a common bearing with the conclusion of two case studies conducted over two decades ago in Bungoma County in the former Western province (Jensen and Juma, 1989) and Kwale County in the former Coast Province (Jensen and Khasakhala, 1993). The two case studies included personal interviews with women and men in rural villages. A broad consensus prevailed between women and men regarding the importance of having many children. Having many children was considered beneficial to the household, both in the short and long-term. In the short-term, children provided household labor, while in the long-term; they acted as old age security. Child mortality was an important factor in sustaining high fertility. Every second woman had experienced the loss of a child in the study areas. It also turned out that women who had lost one or more children had a considerably higher number of births and a higher number of living children compared to women without child death (Jensen and Juma 1989; Jensen and Khasakhala 1993). Thus, child mortality pushed fertility up and so did gender relations. The current study shows that the predicted number of children was highest among women who 
experienced death of a child under-five years. This was the case for both poor and non-poor women across all surveys, though the numbers are relatively high in the former compared with the latter. In both areas, the group with the highest fertility is the poor, who have experienced death of a child under-five years.

The study also examined determinants of individual fertility using Poisson model. The results show that the estimated effects of household wealth and education on fertility vary for Coast and Western provinces. However, the direction of these effects is comparable. In Western province, the effect of household wealth was weak in 19989, 1993 and 1998; however, the effect was stronger in 2003 and 2008/9. By contrast, the effect of household wealth on fertility was inconsistent in Coast province. The result shows a strong effect in 1993, 2003 and 2008/9, a weak effect in 1989 and insignificant effect in 1998. The effect of education on fertility was also unique in Coast and Western provinces. In Coast province, the effect of education was significant except in 1989 when there were no fertility differentials by level of education. In Western province, the effect of education was weak and diminished once other factors were controlled. In both areas, the effect of child mortality was consistent and significant in all the periods. The findings imply that the relationship between household poverty status and fertility depends on the period and is context specific.

The study has certain important limitations worth noting. First, the relationship between fertility and household poverty is not unidirectional but runs from both ways. However, this study focused on the possible effect of household poverty on fertility while ignoring the reverse relationship. Such analysis would require the utility of a panel surveys or longitudinal data to understand the relationship between reproductive outcomes and socio-economic conditions at the micro level (Greene and Merrick 2005). Second, household poverty is known to be transient while fertility is a cumulative of events (Baulch and Hoddinott 2000). However, the current study assumes that there is no mobility in terms of households' socio-economic levels. Such an assumption may not be realistic if movement in and out of poverty is independent of fertility. Thus, the results may underestimate the true relationship between household poverty on fertility.

\section{Conclusion}

The study finds that the relationship between household wealth and fertility vary by context, and they interact to produce distinct patterns. An important finding is that the relationship between a high fertility and household poverty is buttressed by child mortality. Child mortality appeared to push up the fertility in both Coast and Western province, especially among poor households. Fertility decline has been continuous among non-poor women while it remains high among poor women who are also exposed to high child mortality. As result, analysis suggests that the fertility stall may have been fueled by the high childhood mortality among poor women. Moreover, the association between household poverty and fertility is period specific. During the course of the stall in fertility decline, the negative association between poverty and fertility became more pronounced in recent times compared to earlier period. The findings suggest that special attention and targeting are needed to address the needs of the poor and to reduce poverty-related inequalities in access to education and health services to lower the fertility levels.

\section{Acknowledgement}

This paper was part of the author's PhD thesis titled 'Fertility and Household Poverty in Kenya: A Comparative Analysis of Coast and Western Provinces'. The study was contextualized within the wider project 'Poverty and Fertility: the Role of Gender and Reproductive Health' financed by the Norwegian Research Council (NRC) and the William and Flora Hewlett Foundation. Grant no. 199408/S50.Project leader: An-Magritt Jensen

\section{References}

Aassve, A., A.M. Kedir, and H.T. Woldegebrie. 2006. "State Dependence and Causal Feedback of Poverty and Fertility in Ethiopia." in Working Paper, No. 30, Institute for Social and Economic Research. Colchester: University of Essex.

Aassve., A., H. Engelhardt., F. Francavilla., A. Kedir., J. Kim., F. Mealli., L. Mencarini., S. Pudney, and A. Prskawetz. 2005. "Poverty and Fertility in Less Developed Countries: A Comparative Analysis. ISER Working Paper 2005-13." Department of Economics, University of Leicester.

Amin, S., J. B. Casterline, and L. Spess. 2007. Poverty and fertility: evidence and agenda: Population Council. Policy Research, Division.

Arpino, B. and A. Aassve. 2013. "Estimation of causal effects of fertility on economic wellbeing: Data requirements, identifying assumptions and estimation methods." Empirical Economics 44(I):355-385.

Bankole, A. and S. Audam. 2009. "Fertility Preferences and Contraceptive Use in SubSaharan Africa." Presented at Gender Committee 
of IUSSP, August 24-25., African Population and Health Research Center (APHRC) in Nairobi, Kenya.

Baulch, B. and J. Hoddinott. 2000. "Economic mobility and poverty dynamics in developing countries." Journal of Development Studies, 36(6).

Becker, G.S. and H.G. Lewis. 1973. "On the interaction between the quantity and quality of children." Journal of Political Economy 8I(2):Supplement: S279-S288.

Ben-Porath, Y. 1976. "Fertility response to child mortality: micro data from Israel." Journal of Political Economy:SI63-SI78.

Blacker, J. 2002. "Kenya's fertility transition: how low will it go?" in Completing the Fertility Transition (ESA/P/WP.I72/Rev.I). New York: United Nations.

Bollen, K., A., J. Glanville, L. , and G. Stecklos. 2007. "Socio-economic status, Permanent income, and Fertility: A Lantent -Variable Approach." Population Studies 6I(I): I5-34.

Bongaarts, J. 2006. "The Causes of Stalling Fertility Transitions "Studies in Family Planning 37(1): I-16.

—. 2008. "Fertility transitions in developing countries: progress or stagnation?" Stud Fam Plann 39(2): 105-I I0.

Brass, W. and C.L. Jolly. 1993. Population dynamics of Kenya: National Academy Press.

Caldwell, J.C.and P. Caldwell. 1987. "The cultural context of high fertility in sub-Saharan Africa." Population and development review:409-437.

Caldwell, J.C. and T. Schindlmayr. 2003. "Explanations of the Fertility Crisis in Modern Societies: A Search for Communalities." Population Studies 57(3):24I-263.

Canning, D.E. and H. Schofield. 2007. The effect of fertility on female labor supply and household poverty in Indonesia. Boston, MA: Harvard School of Public Health.

CBS, MOH, and ORC Macro. 2004. "Demographic and Health Survey 2003." Central Bureau of Statistics (CBS) [Kenya], Ministry of Health $(\mathrm{MOH})$ [Kenya], and ORC Macro. 2004. Kenya. Calverton, Maryland: CBS, $\mathrm{MOH}$, and ORC Macro.

Cleland, J. and G. Kaufmann. 1998. "Education, fertility, and child survival: Unravelling the links." Pp. 128-152 in The Methods and Uses of Anthropological Demography, edited by A.M. Basu and P. Aaby. Oxford: Clarendon Press.

Cleland, J., J. F. Phillips, S. Amin, and G.M. Kamal. 1994. "The determinants of reproductive change in Bangladesh." World Bank Regional and Sectoral Studies. Washington, DC: The World Bank.

Cross, A. R., W. Obungu., and P. Kizito. 1991. "Evidence of a Transition to Lower Fertility in
Kenya." International Family Planning Perspectives I7(I):4-7.

Egerö, B. 1996. "Poverty and fertility: reproductive change under persistent poverty." Yearbook of population research in Finland 33:218-242.

Filmer, D. and L. Pritchett. 200 I. "Estimating wealth effects without expenditure data - or tears: an application to educational enrollments in states of India." Demography 38(I): I I5-I32.

Garenne, M. 2007. "Situations of fertility stall in subSaharan Africa." in Paper presented at 5th African Population Conf. UAPS. Arusha, Tanzania: 0-14 December 2007.

Greene, M. E. and T. Merrick. 2005. "Poverty reduction: Does reproductive health matter?" in II HNP Discussion Paper. Washington, DC: World Bank.

Gurmu, E. and R. Mace. 2008. "Fertility decline driven by poverty: the case of Addis Ababa, Ethiopia." Journal of biosocial science 40(3):339.

Jensen, A.-M. and M.N. Juma. 1989. "Women, Childbearing and Nutrition. A case study from Bungoma, Kenya." Pp. 293 in NIBR-report no 16,. Oslo.

Jensen, A-M. and A. A. Khasakhala. 1993. "Too Many Children? Fertility and Family Planning in a Muslim Society of Kenya." Pp. 165 in NIBR-report, no I5. OSLO.

Joshi, S. and T. P. Schultz. 2007. "Family planning as an investment in development: evaluation of a program's consequences in Matlab, Bangladesh." Yale University Economic Growth Center Discussion Paper (95I).

Kabeer, N. 200I. "Ideas, Economics and the 'Sociology of Supply': Explanations for Fertility Decline in Bangladesh." Journal of Development Studies 38(I):29-70.

Kedir, A. M., A. Aassve, and H.T. Woldegebriel. 2005. "Simultaneous Random Effect Models of Poverty And Childbearing In Ethiopia." Ethiopian Journal of Economics Vol I4(2): I-32.

KNBSand ICF Macro. 20I0. "Kenya Demographic and Health Survey 2008-09." edited by M. Calverton: Kenya National Bureau of Statistics (KNBS) and ICF Macro.

LeGrand, T., T. Koppenhaver, N. Mondain, and S. Randall. 2003. "Reassessing the Insurance Effect: A Qualitative Analysis of Fertility Behavior in Senegal and Zimbabwe." Population and Development Review 29(3):375-403.

Lipiton, M. 1998. "Population and poverty; how do they interact." in Population and poverty in developing countries, edited by M. Livi-Bacci and D. Gustavo. Oxford: Oxford University Press. 
Lutz, W. 1987. "Factors Associated with the Finnish Fertility Decline Since 1776." Population Studies 4I(3):463-482.

Lutz, W., B.C. O'Neill, and S. Scherbov. 2003. "Europe's Population at a Turning Point." Science 299(56I5): I99|- 1992.

Macrae, S. M., E.K. Bauni, and J.C. Blacker. 200I. "Fertility trends and population policy in Kenya." Pp. 156-185 in Brass Tacks. Essays in Medical Demography, edited by Z. Basia and B. John. London and New York: Athlone

Mason, K. O. 200I. "Gender and Family Systems in the Fertility Transition." Population and Development Review 27:160-I76.

McNicoll, G. 1980. "Institutional determinants of fertility change." Population and Development Review 6:44I-462.

Merrick, T.W. 2002. "Population and poverty: New views on an old controversy." International Family Planning Perspectives:4I-46.

Montgomery, M .R. and P. Hewett, C. 2005. "Urban poverty and health in developing countries: Household and neighborhood effects." Demography 42(3):397-425.

Moultnrie, A.T., V. Hosegood, N. McGrath, C. Hill, K. Herbst, and M.L. Newell. 2008. "Refining the criteria for stalled fertility declines: an application to rural KwaZulu-Natal, South Africa, 1990-2005." Stud Fam Plann 39:39-48.

Noumbissi, A. and J.P. Sanderson. 1998. "Pauvreté et Comportements Démographiques au Cameroun", pp. 149-163 in Crises, Pauvreté et Changements Démographiques dans les pays du Sud edited by F. Gendreau. Paris: Estem.

Nugent, J.B. and R.T. Gillaspy. 1983. "Old age pensions and fertility in rural areas of less developed countries: Some evidence from Mexico." Economic Development and Cultural Change:809-829.

Qizilbash, M. and D. Clark. 2005. "The capability approach and fuzzy poverty measures: an application to the South African context." Social Indicators Research 74(I): 103-139.

Robinson, W.C. 1992. "Kenya Enters the Fertility Transition." Population Studies 46(3):445-457.
Rodriguez, G. and J. Cleland. 198I. "Socio-economic determinants of marital fertility in twenty countries: a multivariate analysis." Presented at World Fertility Survey Conference 1980: Record of Proceedings, Vol.2, Voorburg, Netherlans, International Statistical Institute, 198I.

-. 1988. "Modelling marital fertility by age and duration: an empirical Appraisal of the Page model." Population Studies 42(2):24 I-257.

Rutstein, S.O. and K. Johnson. 2004. "The DHS Wealth Index. DHS Comparative Reports No. 6." Calverton, Maryland: ORC Macro.

Schoumaker, B. 2004. "Poverty and Fertility in SubSaharan Africa: Evidence from 25 Countries." Presented at Population Association of America Meeting, Boston.

-. 2011. "Omissions of recent births in DHS birth histories. Measurement and determinants." in Population Association of Americal annual meeting. Washington DC.

-. 2013. "A Stata module for computing fertility rates and TFRs from birth histories: tfr2." Demographic Research 28(38).

Schoumaker, B. and D. Tabutin. 1999. "Relationship between poverty and fertility inSouthern countries: Knowledge, methodology and cases. Working Paper no 2." Department of Science of Population and Development, Université Catholique de Louvain.

Shapiro, D. and T. Gebreselassie. 2008. "Fertility Transition in Sub-Saharan Africa: Falling and Stalling." African Population Studies 23(I).

Srinivasan, T. N. 1988. "Fertility and old age security in an overlapping generations model." Journal of quantitative economics: journal of the Indian Econometric Society 4(I): I I- I 7.

Westoff, C.F. and A.R. Cross. 2006. "The stall in the fertility transition in Kenya. DHS Analytic Studies, no. 9." Calverton, NY: ORC Macro.

Willis, R.J. 1973. "A new approach to the economic theory of fertility behavior." The Journal of Political Economy:SI4-S64.

Winkelmann, R. and R.K. Zimmermann. 1994. "Count data models for demographicdata." Mathematical Population Studies 4(3):205-22I. 